\title{
Mortality Risk Factors in Preterm Infants Treated with High-Frequency Jet Ventilation
}

\author{
Craig R Wheeler, Holly Stephens, Iris O’Donnell, David Zurakowski, and Craig D Smallwood
}

\begin{abstract}
BACKGROUND: High-frequency jet ventilation (HFJV) has been used in conjunction with conventional ventilation for premature infants with respiratory failure. We sought to identify parameters that were associated with mortality in subjects who underwent HFJV. METHODS: Subjects were enrolled if birthweight was $\leq 2,000 \mathrm{~g}$ and they were $\leq 34$ weeks gestational age. Subjects were excluded if they received HFJV at the time of admission because we aimed to study subjects who failed conventional ventilation. Subject demographics, ventilator parameters, and laboratory data were extracted and analyzed. The Mann-Whitney $U$-test was used to assess differences in continuous variables, and the chi-square and Fisher exact tests were used for categorical variables between the groups. To assess variables that were predictive of mortality, we used both univariate and multivariate logistic regression analysis. Independent predictors of mortality were identified and used to create a multivariate risk score. Receiver operating characteristic curves were constructed to evaluate the predictive accuracy of the multivariate risk score. RESULTS: A total of 53 premature subjects $(n=37$ male) were studied, of whom $39(74 \%)$ survived to discharge or transfer back to referring hospital. In the univariate model, female sex, older gestational age, higher birthweight, HFJV peak inspiratory pressure at $1 \mathrm{~h}$, and oxygen saturation index at $4 \mathrm{~h}$ were associated with mortality. In the final multivariate logistic regression model, female sex (odds ratio 4.1, 95\% CI 1.2-19.8, $P=.044$ ), closed ductus arteriosus (odds ratio $7.7,95 \%$ CI 1.3-39.5, $P=.016$ ), and oxygen saturation index $>5.5$ (odds ratio $6.0,95 \%$ CI 1.5-28.3, $P=.02$ ) were independent predictors of mortality. CONCLUSIONS: We identified that oxygen saturation index $>5.5$ after $4 \mathrm{~h}$ of HFJV, female sex, and closed ductus arteriosus were independent predictors of mortality. Key words: respiratory distress syndrome; prematurity; mechanical ventilation; high-frequency ventilation; high-frequency jet ventilation; bronchopulmonary dysplasia; patent ductus arteriosus; oxygen saturation index. [Respir Care 2020;65(11):1631-1640. (C) 2020 Daedalus Enterprises]
\end{abstract}

\section{Introduction}

Respiratory distress syndrome is the primary cause of respiratory failure in premature infants as a result of lung immaturity, surfactant deficiency, and inadequate gas

Mr Wheeler, Ms Stephens, and Ms O'Donnell are affiliated with the Department of Respiratory Care, Boston Children's Hospital, Boston Massachusetts. Dr Zurakowski is and Dr Smallwood was affiliated with the Department of Anesthesiology, Critical Care and Pain Medicine, Boston Children's Hospital, Boston, Massachusetts, as well as the Harvard Medical School, Boston, Massachusetts.

$\dagger$ Deceased.

Mr Wheeler presented a version of this paper at the OPEN FORUM of the AARC Congress 2019, held November 9-12, 2019, in New Orleans, Louisiana. exchange. ${ }^{1}$ Over the past 2 decades, advances in neonatal care, including antenatal steroids, surfactant replacement therapy, and gentle ventilation strategies, have improved survival of extremely premature infants. ${ }^{2}$ Current care includes early utilization of CPAP to reduce respiratory distress, ventilator-induced lung injury, and risk of bronchopulmonary dysplasia., ${ }^{3,4}$ Despite increased utilization of noninvasive respiratory support including CPAP, approximately $50 \%$ of

\footnotetext{
The authors have disclosed no conflicts of interest.

Correspondence: Craig R Wheeler MSc RRT RRT-NPS, Department of Respiratory Care, Boston Children's Hospital, 300 Longwood Ave, Boston, MA 02115. E-mail: craig.wheeler@childrens.harvard.edu.
}

DOI: $10.4187 /$ respcare. 07600 


\section{Mortality Risk Factors in Preterm InFAnTS TREATED with HFJV}

infants $<28$ weeks gestational age still require intubation. ${ }^{5,6}$ Additionally, $70 \%$ of infants receive invasive mechanical ventilation preceding initiation of CPAP. As such, invasive

\section{See the Related Editorial on Page 1784}

conventional mechanical ventilation continues to be a primary respiratory support modality for premature infants with respiratory distress syndrome. Although lifesaving, mechanical ventilation in preterm infants has been associated with higher rates of mortality and morbidities such as the development of bronchopulmonary dysplasia and neurodevelopmental impairment. ${ }^{7}$ A subset of infants are managed with highfrequency ventilation (HFV) as the primary mode of ventilation, whereas others exhibit persistent respiratory failure despite maximal lung-protective conventional ventilation strategies and are transitioned to HFV for rescue. Overall, studies comparing the use of high-frequency oscillatory ventilation (HFOV) and high-frequency jet ventilation (HFJV) to conventional mechanical ventilation have not demonstrated significant benefits in outcomes for elective or rescue usage ${ }^{8,9} \mathrm{HFV}$ utilization has increased over the past decade with $28-62 \%$ of infants born between 22 and 28 weeks gestational age receiving some type of HFV. ${ }^{1,10}$ However, risk factors associated with conventional mechanical ventilation failure and the need for HFJV have not been adequately described, and no predictive tools exist to aid bedside clinicians in deciding if and when HFJV should be initiated. Therefore, we sought to characterize factors associated with premature infants who failed conventional mechanical ventilation and underwent rescue HFJV and develop a risk score that could be used to predict outcome of patients receiving HFJV. We hypothesized that differences in postnatal risk factors and physiologic parameters would be observed in subjects who survived, when compared with those who died. The aim of this study was to identify risk factors associated with mortality in premature infants who received rescue HFJV.

\section{Methods}

\section{Subjects}

All subjects were outborn (ie, not born at our institution) and transferred to Boston Children's Hospital neonatal ICU for further management. This retrospective analysis of infants admitted to the neonatal ICU who underwent HFJV between January 2015 and January 2019 qualified for expedited review and was approved by the institutional review board. Subjects were included in the study if birthweight was $<2,000 \mathrm{~g}$, gestational age was $<34$ weeks, and they received HFJV. Gestational age and weight were categorized according established critieria. ${ }^{11}$ Indications for HFJV include severe respiratory failure secondary to respiratory

\section{QUICK LOOK}

\section{Current knowledge}

Use of rescue high-frequency jet ventilation (HFJV) in premature infants with respiratory failure is an accepted standard of care in most neonatal ICUs. There are no established guidelines for the use of HFJV as a rescue strategy, and the body of literature on this topic is inconclusive.

\section{What this paper contributes to our knowledge}

In a retrospective review of premature subjects with respiratory failure refractory to conventional ventilation, HFJV was used as a rescue mode of ventilation. In this cohort, female sex, closed ductus arteriosus, and oxygen saturation index $>5.5$ after $4 \mathrm{~h}$ of HFJV were independent predictors of mortality. Based on these data, we created a multivariate risk score to facilitate early identification of infants who are at higher risk for clinical decompensation and death.

distress syndrome ( $\mathrm{pH}<7.25$, hypercarbia, or hypoxia) despite maximum conventional mechanical ventilation settings, asymmetric lung injury, and air leak syndrome. The timing of transition to HFJV was left to the discretion of the medical team. Subjects with complex congenital heart disease or congenital diaphragmatic hernia and those who underwent HFJV or HFOV as the initial mode of ventilation upon admission were excluded from this study.

All subjects were initially ventilated with either a Servo-i or Servo-u (Getinge AB, Gothenburg, Sweden) in pressure control intermittent mandatory ventilation mode before conversion to Life Pulse HFJV (Bunnell, Salt Lake City, Utah). All endotracheal tube adapters were exchanged with the LifePort adapter (Bunnell Inc., Salt Lake City, Utah) of appropriate size to permit HFJV monitoring and regulation of proximal airway pressures according to manufacturer recommendations. The conventional ventilator was used in tandem with HFJV to provide PEEP, sigh-breaths, bias flow, and an exhalation valve as specified by manufacturer recommendations. All equipment was calibrated according to manufacturer specifications before application.

Subjects were converted to HFJV in accordance with institutional guidelines, which have been described in a previous publication and are highlighted in Figure $1 .{ }^{12}$ HFJV peak inspiratory pressure was primarily adjusted to maintain a $\mathrm{pH} \geq 7.25$ and capillary $\mathrm{P}_{\mathrm{CO}_{2}}$ of $45-60 \mathrm{~mm} \mathrm{Hg}$. $\mathrm{F}_{\mathrm{IO}_{2}}$ was titrated to maintain $\mathrm{S}_{\mathrm{pO}_{2}}$ between $88 \%$ and $94 \%$. If $\mathrm{F}_{\mathrm{IO}_{2}}$ could not be weaned to $<0.6$, PEEP was increased in increments of $1-2 \mathrm{~cm} \mathrm{H}_{2} \mathrm{O}$ until this target was met. 


\section{Mortality Risk Factors in Preterm Infants Treated With HFJV}



Fig. 1. Algorithm of high-frequency jet ventilation management guideline. *Adjust settings: (1) increase PEEP $\sim 2 \mathrm{~cm} \mathrm{H}_{2} \mathrm{O}$ to achieve similar (or slightly higher) $\overline{\mathrm{P}}_{\mathrm{aw}}$ as on conventional ventilation; (2) set HFJV PIP at $3-5 \mathrm{~cm} \mathrm{H} \mathrm{H}_{2} \mathrm{O}$ conventional ventilation PIP and observe chest vibration; (3) reduce frequency to 2-5 breaths/min or ideally CPAP for air leak. †Air trapping is a difference of $\geq 2 \mathrm{~cm} \mathrm{H}_{2} \mathrm{O}$ in monitored PEEP between HFJV and conventional ventilation, or hyperinflation on chest radiograph. ‡lncreasing on-time may improve gas exchange in larger infants or those with increased airway resistance. Longer on-times may necessitate reducing HFJV frequency (eg, 240-360) to afford adequate time for passive exhalation. §Extubation from HFJV may be considered when $\overline{\mathrm{P}}_{\text {aw }}$ can be replicated with nasal CPAP $\left(\mathrm{eg},<10 \mathrm{~cm} \mathrm{H}_{2} \mathrm{O}\right)$. $\|$ Decreasing PEEP results in $\uparrow \Delta \mathrm{P}$ and potentially hypocarbia; if $\mathrm{pH}$ and $\mathrm{P}_{\mathrm{CO}_{2}}$ are within range, simultaneously wean HFJV PIP and PEEP to maintain the same $\Delta \mathrm{P}$. $\uparrow$ Rapid reductions in HFJV PIP will decrease $\overline{\mathrm{P}}_{\mathrm{aw}}$; consider reducing $\Delta \mathrm{P}$ by increasing PEEP in infants with atelectasis or $\mathrm{F}_{1 \mathrm{O}_{2}} \geq 0.6$. $\mathrm{ETT}=$ endotracheal tube. $\mathrm{f}=\mathrm{HFJV}$ frequency is selected based on suspected pulmonary time constants (eg, respiratory distress syndrome 420 or bronchopulmonary dysplasia $240-360$ breaths $/ \mathrm{min}) . \overline{\mathrm{P}}_{\mathrm{aw}}=$ mean airway pressure. $\Delta \mathrm{P}=\mathrm{HFJV} \mathrm{PIP}$ minus $\mathrm{PEEP}_{\mathrm{P}} \mathrm{P}_{\mathrm{tccO}}=\mathrm{transcutane}_{2}$ ously measured partial pressure of carbon dioxide. HFOV = high-frequency oscillatory ventilation.

\section{Data Collection}

Subject demographics and ventilator, physiologic, and laboratory data were collected for analysis. Demographic and neonatal factors included gestational age, postmenstrual age, birthweight, antenatal steroid use, surfactant replacement therapy, nitric oxide, mechanical ventilation settings, and physiologic data. Ventilator parameters and physiologic data including $\mathrm{pH}$ and $\mathrm{P}_{\mathrm{CO}_{2}}$ were extracted from the electronic medical record and analyzed prior to HFJV and at 1, 4,6 , and $12 \mathrm{~h}$ following conversion to HFJV. Oxygen saturation index (OSI) was calculated as mean airway pressure $x$ $\mathrm{F}_{\mathrm{IO}_{2}} \times 100 / \mathrm{S}_{\mathrm{pO}_{2}}$.

The primary outcome was all-cause mortality before discharge from the neonatal ICU. Secondary outcomes included the development of severe bronchopulmonary dysplasia defined using the National Institute of Child Health criteria (ie, $\mathrm{F}_{\mathrm{IO}_{2}} \geq 0.3$ or positive-pressure ventilation at 36 weeks postmenstrual age), ${ }^{13,14}$ successful extubation defined as not requiring re-intubation within 1 week, ${ }^{15}$ necrotizing enterocolitis, intraventricular hemorrhage $\geq$ grade 3 , and retinopathy of prematurity $>$ grade $2 .{ }^{16}$

\section{Statistical Analysis}

The cohort was divided into survivors and nonsurvivors. Prism 8.1.1 (GraphPad Software, La Jolla, California) and SPSS 24 (IBM Armonk, New York) were used for analysis. Mann-Whitney $U$-test was used to assess differences in continuous variables, and the chi-square and Fisher exact tests were used for categorical variables. To assess variables that were predictive of mortality, we used both univariate and multivariate logistic regression analysis. Independent predictors of mortality were identified and used to create a multivariate risk score. Receiver operating characteristic curves were constructed to evaluate the 


\section{Mortality Risk Factors in Preterm InFAnTS TREATED with HFJV}

predictive accuracy of the multivariate risk score. The optimal cutoff for OSI was determined with the Youden J-index in receiver operating characteristic analysis. Because the data were not normally distributed, they are reported as median (interquartile range). All tests were 2 -sided, and $P$ values $<.05$ were considered significant.

\section{Results}

A total of 53 premature subjects $(n=37$ male) were studied, of whom 39 (74\%) survived to discharge or transfer back to referring hospital. The major diseases and conditions requiring rescue HFJV included respiratory distress syndrome $(41 \%)$, patent ductus arteriosus $(37 \%)$, sepsis (17\%), and air leak syndrome (5\%). Surgical closure of the ductus arteriosus was accomplished via ligature $(40 \%)$ or clip $(60 \%)$ at a median (interquartile range) of 18.5 (15.829.8) days of life for survivors and 30 (19-41) days of life in the 2 nonsurvivors with PDA. Primary cause of death was attributed to intestinal perforation (29\%), redirection due to futility (29\%), cardiopulmonary arrest (21\%), sepsis (14\%), and hydrops (7\%). Nonsurvivors were older and underwent HFJV at a later postmenstrual age than survivors. Blood gas data from arterial (25\%), capillary $(70 \%)$, or venous $(5 \%)$ samples were included, provided that test values were obtained within $30 \mathrm{~min}$ before or after each predefined time interval. Demographic characteristics and postnatal factors are displayed in Table 1. Before conversion to HFJV, there were no significant differences between survivors and nonsurvivors in the median conventional peak inspiratory pressure, frequency, tidal volume, mean airway pressure, $\mathrm{pH}$, and capillary $\mathrm{P}_{\mathrm{CO}_{2}}$. Median (range) PEEP level was higher in surviving subjects at $6(5-8) \mathrm{cm}$ $\mathrm{H}_{2} \mathrm{O}$ compared with nonsurvivors at 5 (4-7) $\mathrm{cm} \mathrm{H}_{2} \mathrm{O}(P=$ .02 ). Trends in mechanical ventilation and physiologic data are displayed in Table 2. In the univariate model, the following variables were associated with mortality: sex, gestational age, postmenstrual age at time of HFJV, birthweight, stay, arterial access at time of HFJV, utilization of inhaled nitric oxide, HFJV peak inspiratory pressure at $1 \mathrm{~h}$, and OSI at $4 \mathrm{~h}$ (Table 1). In the final multivariate logistic regression model, female sex, closed ductus arteriosus, and OSI $>5.5$ were independent predictors of mortality (Table 3). Based on the data shown in Table 3, we created a multivariate risk score as the sum of the 3 predictors, each weighted as 1 point. Thus, the risk score can range from 0 to 3 points. Median (range) of the multivariate risk score was $1(0-3)$ points for survivors and $2(1-3)$ points for nonsurvivors $(P<.001$, Mann-Whitney $U$-test $)$. The area under the receiver operating characteristic curve was 0.800 (95\% CI $0.664-0.936, P<.001$ ). The best cutoff value for risk stratification is a risk score of at least 2 points, corresponding to a sensitivity of $79 \%$ and a specificity of $78 \%$, as shown in Figure 2. Predicted probability of mortality according to OSI at $4 \mathrm{~h}$ stratified by sex and ductus arteriosus status (open vs closed) are displayed in Figure 3. Surviving subjects had the following outcomes: 11 (28\%) were extubated successfully; 19 (49\%) remained intubated and were transferred back to the referring hospital before 36 weeks; 9 (23\%) were classified as having bronchopulmonary dysplasia (7 severe and 2 moderate); and 5 (13\%) had documented retinopathy of prematurity $>$ stage 2 .

\section{Discussion}

Despite improved survival among premature infants, approximately $25 \%$ of extremely premature infants born at 22-28 weeks gestational age do not survive. ${ }^{17}$ Consistent with these findings, $74 \%$ of subjects in our study survived to hospital discharge or transfer to another facility although early deaths attributed to pulmonary dysfunction have decreased, with extremely premature infants surviving longer but with elevated risk for late-onset sepsis, necrotizing enterocolitis, or the development of bronchopulmonary dysplasia and retinopathy of prematurity. ${ }^{11}$ Our cohort consisted of $70 \%$ males; however, females accounted for $57 \%$ of the nonsurvivors. This finding contrasts with previous reports that have suggested female infants on average have better outcomes than their male counterparts. ${ }^{11,18}$ Because all subjects were outborn, the higher proportion of female mortality may have been influenced by referral patterns for surgical intervention, extreme prematurity, comorbidities, worsened disease severity, or unmeasured covariates. Three of the nonsurviving subjects were more mature (31-33 weeks gestational age) and weighed more (1,800-1,950 g). It is likely that the inclusion of these subjects skewed the weight distribution and resulted in the finding that survivors weighed more than nonsurvivors.

A recent prospective observational multi-center study on rescue HFOV in neonates failing conventional ventilation reported that rescue HFOV was successful in improving gas exchange in 58\% of subjects. ${ }^{19}$ Although demographic and treatment characteristics at baseline were similar between groups, subjects who died had lower birthweight $(1,655 \pm 1,091$ vs $1,858 \pm 1,027 \mathrm{~g}$, $P=.004)$, higher initial $\mathrm{F}_{\mathrm{IO}_{2}}(0.83$ vs $0.72, P<.001)$, and higher rate of exposure to inhaled nitric oxide (22\% vs $11 \%, P=.004)$ compared with survivors. Moreover, survivors demonstrated a mean reduction in oxygenation index after $1 \mathrm{~h}$ of HFOV, whereas nonsurvivors did not improve. We observed a similar response in gas exchange following rescue with $\mathrm{HFJV}$, as $\mathrm{pH} \geq 7.25$ and $\mathrm{F}_{\mathrm{IO}_{2}} \leq 0.4$ were achieved in $54 \%$ and $60 \%$ of all subjects by 4-h. In our study, nonsurvivors demonstrated a nonsignificantly higher $\mathrm{F}_{\mathrm{IO}_{2}}$ at baseline (0.5 vs $0.35, P=.049)$, a higher median OSI after $4 \mathrm{~h}(7 \mathrm{vs} 4$, $P=.03)$, and a higher rate of inhaled nitric oxide exposure $(29 \%$ vs $5 \%, P=.036)$. 


\section{Mortality Risk Factors in Preterm InFAnTS TREATED with HFJV}

Table 1. Subject Demographics

\begin{tabular}{|c|c|c|c|}
\hline Variable & Survivors & Nonsurvivors & $P$ \\
\hline Sex & & & .02 \\
\hline Male & $31(80)$ & $6(43)$ & \\
\hline Female & $8(20)$ & $8(57)$ & \\
\hline Gestational age, weeks & $25.1(24.1-26.6)$ & $28.4(24.9-31.1)$ & .02 \\
\hline Postmenstrual age at time of HFJV, weeks & $27.7(24.1-28.9)$ & $29.5(26.5-31.2)$ & .044 \\
\hline \multicolumn{4}{|l|}{ Premature births } \\
\hline Extremely premature $(<28$ weeks $)$ & $34(87)$ & $6(43)$ & .002 \\
\hline Very premature ( $28<32$ weeks $)$ & $5(13)$ & $7(50)$ & .008 \\
\hline Moderate premature $(32<34$ weeks $)$ & $0(0)$ & $1(7)$ & .26 \\
\hline Weight, g & $800(670-1,000)$ & $1200(790-1,600)$ & .039 \\
\hline Extremely low birthweight $(<1,000 \mathrm{~g})$ & $23(56)$ & $5(36)$ & .21 \\
\hline Very low birthweight $(<1,500 \mathrm{~g})$ & $14(36)$ & $6(43)$ & .75 \\
\hline Low birthweight $(<2,500 \mathrm{~g})$ & $2(5)$ & $3(21)$ & .11 \\
\hline Apgar, $1 \mathrm{~min}$ & $3(1.5-6)$ & $4(2-4.5)$ & .85 \\
\hline Apgar, $5 \mathrm{~min}$ & $7(4-8)$ & $6(4.5-7)$ & .35 \\
\hline Surfactant & $36(92 \%)$ & $10(86 \%)$ & .60 \\
\hline Antenatal steroids & $18(46 \%)$ & $7(50 \%)$ & .75 \\
\hline Intraventricular hemorrhage $\geq$ grade 3 & $8(20 \%)$ & $3(21 \%)$ & .99 \\
\hline Necrotizing entercolitis & $11(28 \%)$ & $2(14 \%)$ & .47 \\
\hline Duration of conventional mechanical ventilation, $\mathrm{h}$ & $72(13-216)$ & $39.5(13-315)$ & .99 \\
\hline Duration of HFJV, h & $72(33-119)$ & $68.5(28.8-316)$ & .57 \\
\hline Total duration, $\mathrm{h}$ & $306(139-649)$ & $315.5(50.8-780)$ & .64 \\
\hline Length of stay, $d$ & $36(8-67)$ & $10(2-28.5)$ & .02 \\
\hline Arterial access & $7(18 \%)$ & $6(43 \%)$ & .002 \\
\hline Inhaled nitric oxide & $2(5 \%)$ & $4(29 \%)$ & .036 \\
\hline Patent ductus arteriosus ${ }^{\dagger}$ & $18(46 \%)$ & $2(14 \%)$ & .05 \\
\hline Ductus arteriosus & & & .31 \\
\hline Open & $7(18)$ & $1(7)$ & \\
\hline Closed & $32(82)$ & $13(93)$ & \\
\hline PEEP, $\mathrm{cm} \mathrm{H}_{2} \mathrm{O}$ & $6(5-8)$ & $5(4-7)$ & .064 \\
\hline $\mathrm{F}_{\mathrm{IO}_{2}}$ & $0.4(.21-1.0)$ & $0.5(.21-1.0)$ & .050 \\
\hline PIP at $1 \mathrm{~h}$ after $\mathrm{HFJV}, \mathrm{cm} \mathrm{H}_{2} \mathrm{O}$ & $26(20-42)$ & $29(20-43)$ & .044 \\
\hline Oxygen saturation index at $4 \mathrm{~h}$ after HFJV & $4(2-18)$ & $7(3-13)$ & .03 \\
\hline \multicolumn{4}{|c|}{$\begin{array}{l}\text { Continuous data are presented as median (interquartile range); categorical data are presented as } n(\%) \text {. } \\
\text { "Diagnosis upon admission with surgical closure during hospitalization. } \\
\text { HFJV = high-frequency jet ventilation } \\
\text { PIP = peak inspiratory pressure }\end{array}$} \\
\hline
\end{tabular}

We observed that an OSI $>5.5$ was independently associated with a 6-fold increase in mortality for subjects undergoing HFJV. Historically, the oxygen index, calculated as the mean airway pressure $\times \mathrm{F}_{\mathrm{IO}_{2}} \times 100 / \mathrm{P}_{\mathrm{aO}}$, was utilized to assess the severity of respiratory illness, direct interventions, and evaluate response to therapies such as surfactant, $\mathrm{HFV}$, and inhaled nitric oxide. ${ }^{20-22}$ In contemporary practice, umbilical lines are time-limited and the routine placement of peripheral arterial lines in premature infants is infrequent due to small patient size or concern for increased risk of infection, thrombosus, iatrogenic anemia, and ischemia. ${ }^{23-25}$ The lack of arterial access precludes infants from the routine calculation of the oxygen index and subsequent risk stratification. Notably, only $25 \%$ of subjects in our study had arterial access, with a significantly higher proportion in nonsurvivors ( $43 \%$ vs $18 \%, P=.002$ ). OSI (ie, mean airway pressure $\times \mathrm{F}_{\mathrm{IO}_{2}} \times 100 / \mathrm{S}_{\mathrm{pO}_{2}}$ ) has a strong linear correlation with the oxygen index and had been validated as a noninvasive method for assessing the severity of respiratory illness in infants and children. ${ }^{26-28}$ Recently, Muniraman et $\mathrm{al}^{29}$ demonstrated that the oxygen index derived from OSI was strongly correlated $(\mathrm{r}=0.89)$ and may provide reliable assessment of respiratory failure on a continuous basis. The authors reported stronger correlation $(r=0.93)$ in subjects $<28$ weeks gestational age within an oxygen saturation range of $85-5 \%(\mathrm{r}=0.94)$. Further, Khalesi et al ${ }^{30}$ reported the predictive capability of OSI in premature infants and identified that an OSI cutoff $\geq$ 


\section{Mortality Risk Factors in Preterm InFAnTS TREATED with HFJV}

Table 2. Mechanical Ventilation and Physiologic Variable Trends During HFJV

\begin{tabular}{|c|c|c|c|}
\hline Variable & Survivors & Nonsurvivors & $P$ \\
\hline \multicolumn{4}{|l|}{ Pre-HFJV } \\
\hline Conventional mechanical ventilation $\mathrm{PIP}, \mathrm{cm} \mathrm{H}_{2} \mathrm{O}$ & $20(18.3-23.8)$ & $21.5(17.8-25.5)$ & .48 \\
\hline Tidal volume, $\mathrm{mL} / \mathrm{kg}$ & $7(6-8)$ & $8(6.8-8.3)$ & .10 \\
\hline Frequency, breaths/min & $40(38-44)$ & $42(37.5-45)$ & .30 \\
\hline $\mathrm{PEEP}, \mathrm{cm} \mathrm{H} \mathrm{H}_{2} \mathrm{O}$ & $6(5-6)$ & $5(5-6)$ & .02 \\
\hline Mean airway pressure, $\mathrm{cm} \mathrm{H}_{2} \mathrm{O}$ & $10(9-12)$ & $10(8.5-12.5)$ & .64 \\
\hline $\mathrm{F}_{\mathrm{IO}_{2}}$ & $0.35(0.30-0.60)$ & $0.50(0.36-0.60)$ & .049 \\
\hline $\mathrm{S}_{\mathrm{pO}_{2}}, \%$ & $95(93-97)$ & $93.5(92-97)$ & .66 \\
\hline Oxygen saturation index & $3.9(2.8-5.1)$ & $3.8(2.3-7.9)$ & .68 \\
\hline $\mathrm{pH}$ & $7.14(7.04-7.19)$ & $7.08(7.02-7.17)$ & .33 \\
\hline Capillary $\mathrm{P}_{\mathrm{CO}_{2}}, \mathrm{~mm} \mathrm{Hg}$ & $74(67-90)$ & $72(51-74)$ & .09 \\
\hline \multicolumn{4}{|l|}{ HFJV after $1 \mathrm{~h}$} \\
\hline HFJV PIP, $\mathrm{cm} \mathrm{H}_{2} \mathrm{O}$ & $26(24-30)$ & $29(25.8-35.3)$ & .044 \\
\hline PEEP, $\mathrm{cm} \mathrm{H}_{2} \mathrm{O}$ & $7(7-8)$ & $7.5(6-8)$ & .60 \\
\hline Mean airway pressure, $\mathrm{cm} \mathrm{H}_{2} \mathrm{O}$ & $11.3(9.8-12.3)$ & $11(10.9-13.1)$ & .45 \\
\hline $\mathrm{F}_{\mathrm{IO}_{2}}$ & $0.4(0.3-0.5)$ & $0.5(0.33-0.97)$ & .27 \\
\hline $\mathrm{S}_{\mathrm{pO}_{2}}, \%$ & $96(93-98)$ & $95(92.5-98.5)$ & .78 \\
\hline Oxygen saturation index & $5(3.2-7.1)$ & $7.2(3.5-12)$ & .21 \\
\hline $\mathrm{pH}$ & $7.25(7.2-7.31)$ & $7.26(7.04-7.37)$ & .54 \\
\hline Capillary $\mathrm{P}_{\mathrm{CO}_{2}}, \mathrm{~mm} \mathrm{Hg}$ & $54(41-68)$ & $45(33-59)$ & .22 \\
\hline \multicolumn{4}{|l|}{ HFJV after $4 \mathrm{~h}$} \\
\hline HFJV PIP, $\mathrm{cm} \mathrm{H}_{2} \mathrm{O}$ & $27(23.8-30)$ & $28(25.8-38)$ & .13 \\
\hline PEEP, $\mathrm{cm} \mathrm{H}_{2} \mathrm{O}$ & $7(7-9)$ & $7(6-8)$ & .64 \\
\hline Mean airway pressure, $\mathrm{cm} \mathrm{H}_{2} \mathrm{O}$ & $10.8(9.5-11.9)$ & $11.3(9.7-12.1)$ & .59 \\
\hline $\mathrm{F}_{\mathrm{IO}_{2}}$ & $0.34(0.25-0.46)$ & $0.5(0.33-0.89)$ & .03 \\
\hline $\mathrm{S}_{\mathrm{pO}_{2}}, \%$ & $95(92-97)$ & $93(9.5-97)$ & .39 \\
\hline Oxygen saturation index & $4(2.7-5.4)$ & $6.7(3.9-10)$ & .03 \\
\hline $\mathrm{pH}$ & $7.26(7.18-7.33)$ & $7.26(7.16-7.32)$ & .67 \\
\hline Capillary $\mathrm{P}_{\mathrm{CO}_{2}}, \mathrm{~mm} \mathrm{Hg}$ & $55.4(44.3-64.3)$ & $48(40.8-57.8)$ & .11 \\
\hline \multicolumn{4}{|l|}{ HFJV after $6 \mathrm{~h}$} \\
\hline HFJV PIP, $\mathrm{cm} \mathrm{H}_{2} \mathrm{O}$ & $28(24-30)$ & $29(25.5-36)$ & .18 \\
\hline PEEP, $\mathrm{cm} \mathrm{H}_{2} \mathrm{O}$ & $8(7-9)$ & $7.5(6-8.8)$ & .56 \\
\hline Mean airway pressure, $\mathrm{cm} \mathrm{H}_{2} \mathrm{O}$ & $10.7(9.5-11.1)$ & $10.8(9.4-12.2)$ & .50 \\
\hline $\mathrm{F}_{\mathrm{IO}_{2}}$ & $0.35(0.25-0.45)$ & $0.6(0.25-0.97)$ & .14 \\
\hline $\mathrm{S}_{\mathrm{pO}_{2}}, \%$ & $96(94-98)$ & $95(92-98)$ & .30 \\
\hline Oxygen saturation index & $3.6(2.8-5)$ & $6(2.9-11)$ & .08 \\
\hline $\mathrm{pH}$ & $7.26(7.2-7.35)$ & $7.25(7.2-7.32)$ & .65 \\
\hline Capillary $\mathrm{P}_{\mathrm{CO}_{2}}, \mathrm{~mm} \mathrm{Hg}$ & $51(4.5-64.5)$ & $47(38.8-6.3)$ & .53 \\
\hline \multicolumn{4}{|l|}{ HFJV after $12 \mathrm{~h}$} \\
\hline $\mathrm{HFJV} \mathrm{PIP}, \mathrm{cm} \mathrm{H}_{2} \mathrm{O}$ & $27(24-30)$ & $28.5(23-34.5)$ & .43 \\
\hline PEEP, $\mathrm{cm} \mathrm{H}_{2} \mathrm{O}$ & $8(7-8.5)$ & $8(6-9)$ & .96 \\
\hline Mean airway pressure, $\mathrm{cm} \mathrm{H}_{2} \mathrm{O}$ & $10.7(9.4-12)$ & $11(9.5-12.7)$ & .65 \\
\hline $\mathrm{F}_{\mathrm{IO}_{2}}$ & $0.35(0.28-0.45)$ & $0.4(0.28-0.81)$ & .58 \\
\hline $\mathrm{S}_{\mathrm{pO}_{2}}, \%$ & $95.5(93-97)$ & $94.5(92.5-96.3)$ & .55 \\
\hline Oxygen saturation index & $4.3(3-5.4)$ & $4.6(3.2-9.4)$ & .55 \\
\hline $\mathrm{pH}$ & $7.29(7.19-7.35)$ & $7.27(7.22-7.34)$ & .79 \\
\hline Capillary $\mathrm{P}_{\mathrm{CO}_{2}}, \mathrm{~mm} \mathrm{Hg}$ & $50(44-61)$ & $43.5(38.2-53)$ & .07 \\
\hline \multicolumn{4}{|l|}{$\begin{array}{l}\text { Results are presented as median and interquartile range. } \\
\text { HFJV = high-frequency jet ventilation } \\
\text { PIP = peak inspiratory pressure }\end{array}$} \\
\hline
\end{tabular}




\section{Mortality Risk Factors in Preterm InFAnTS TREATED with HFJV}

Table 3. Results from Multivariate Logistic Regression Model of Independent Predictors of Mortality

\begin{tabular}{lcc}
\hline \hline \multicolumn{1}{c}{ Predictor } & Odds Ratio (95\% CI) & $P$ \\
\hline Sex (female vs male) & $4.1(1.2-19.8)$ & $.044^{*}$ \\
Patent ductus arteriosus (closed vs open) & $7.7(1.3-39.5)$ & $.02^{*}$ \\
Oxygen saturation index at 4 $\mathrm{h}>5.5^{\dagger}$ & $6.0(1.5-28.3)$ & $.02^{*}$
\end{tabular}

* Significant multivariate predictor.

${ }^{\dagger}$ The optimal cutoff value for oxygen saturation index was determined with the Youden J-index in receiver operating characteristic analysis.

8 was equal to oxygen index of 15 and had excellent diagnostic value for assessment of respiratory failure severity with a sensitivity of $100 \%$ and a specificity of $98 \%$. Previously, we reported that premature subjects who initially exhibited a poor response to HFJV had elevated OSI and $\mathrm{F}_{\mathrm{IO}_{2}}$ after $4 \mathrm{~h}$ compared with responders (7.25 vs $3.36, P=$ .03 ) and (0.6 vs $0.35, P=.038)$, respectively. ${ }^{12}$ Collectively, these findings suggest that OSI is a useful metric for guiding interventions, evaluating treatment response, and identifying risk stratification in premature infants, and our results support these findings.

Our data suggest that ductal patency confers a survival benefit because subjects who did not have a patent ductus arteriosus demonstrated a nearly 8 -fold increase in mortality. Patent ductus arteriosus is inversely related to gestational age, occurring in up to $70 \%$ of extremely premature infants beyond the postnatal transition period and has been associated with increased risk of bronchopulmonary dysplasia, hemorhagic pulmonary edema, necrotizing enterocolitis, intraventricular hemorrhage, and retinopathy of prematurity. ${ }^{31}$ In our study, $38 \%$ of subjects underwent surgical closure of the ductus arteriosus; 8 subjects were rescued with HFJV perioperatively, whereas the remaining 12 underwent rescue HFJV within $24 \mathrm{~h}$ following surgery. Our study was not designed to discern the impact of ductal patency on outcomes because patent ductus arteriosus was considered a categorical variable and we did not control for clinically important factors such as the relative pressure differences between pulmonary and systemic circulations, and size or duration of significant ductus arteriosus. ${ }^{31-33}$ Preoperatively, the progressive reduction of pulmonary vascular resistance, increased left-to-right shunt, and subsequent pulmonary overcirculation compounds underlying respiratory distress syndrome via mechanisms of pulmonary edema formation. This results in further reduction of respiratory system compliance and worsened gas exchange. ${ }^{32}$ Smaller observational studies have evaluated the effect of lung recruitment using higher levels of PEEP or mean airway pressure on pulmonary, systemic, and ductal blood flow. ${ }^{33,34}$ Fajardo et $\mathrm{al}^{35}$ compared PEEP of $5 \mathrm{~cm} \mathrm{H}_{2} \mathrm{O}$ with $8 \mathrm{~cm} \mathrm{H}_{2} \mathrm{O}$ and reported that mild reductions in left-toright shunt through the ductus arteriosus was associated with



Fig. 2. Multivariate risk score and associated patient mortality. Based on Table 3, we created a multivariate risk score as the sum of the 3 predictors, each weighted as 1 point. Thus, the risk score can range from 0 to 3 points. The median (range) of the multivariate risk score was 1 point (0-3) for survivors and 2 points (1-3) for nonsurvivors $(P<.001$, Mann-Whitney $U$-test). Area under the receiver operating characteristic curve (AUC) showed excellent predictive accuracy of the multivariate risk score (area under the curve = $0.800,95 \% \mathrm{Cl} 0.664-0.936, P<.001)$. The best cutoff value for risk stratification is a risk score of $\geq 2$ points, corresponding to a sensitivity of $79 \%$ and a specificity of $78 \%$, as shown in the receiver operating characteristic figure.

PEEP of $8 \mathrm{~cm} \mathrm{H}_{2} \mathrm{O}$. In contrast, de Waal and colleagues ${ }^{34}$ prospectively studied the effect of lung recruitment on a cohort of mostly premature infants receiving HFOV and observed no differences in superior vena cava flow or ductal shunting when comparing mean airway pressures of $8 \mathrm{~cm}$ $\mathrm{H}_{2} \mathrm{O}$ and $20 \mathrm{~cm} \mathrm{H}_{2} \mathrm{O}$. Noonan et $\mathrm{al}^{36}$ compared the routine intraoperative management of preterm subjects who received HFJV to those transitioned to conventional mechanical ventilation for surgery and reported that mode of ventilation did not affect surgical morbidity, mortality, or short-term clinical outcomes. Additionally, these authors noted that subjects who underwent HFJV had lower $\mathrm{P}_{\mathrm{aCO}}$ than the conventional mechanical ventilation group (54 vs $48 \mathrm{~mm} \mathrm{Hg}, P=.006$ ) at $12 \mathrm{~h}$ after the procedure. Moreover, it is important to consider that right-to-left shunt through the ductus arteriosus is relatively common in mechanically ventilated neonates with respiratory distress syndrome, and lung recruitment, $\mathrm{pH}$, and $\mathrm{P}_{\mathrm{aCO}}$ have differing effects on pulmonary vascular resistance and therefore shunt direction. ${ }^{33}$

Conversely, surgical closure of the ductus arteriosus results in an abrupt reduction in pulmonary blood flow and left ventricular preload with concurrently increased left ventricular afterload and decreased contractility, stroke volume, left ventricular output, and systemic arterial pressure. ${ }^{37}$ In theory, surgical closure of the ductus arteriosus should 


\section{Mortality Risk Factors in Preterm Infants Treated with HFJV}



Fig. 3. Predicted probability of mortality according to the oxygen saturation index (OSI) at $4 \mathrm{~h}$ stratified by sex and ductus arteriosus (DA) status (open vs closed) at time of high-frequency jet ventilation.

improve lung compliance and respiratory morbidities; however, there is a paucity of conclusive evidence in this area. ${ }^{38-40}$ Additionally, pulmonary function may be altered during surgical closure of the ductus arteriosus because it requires thoracotomy, dissection, and instrumentation of the lung and has been associated with complications including pneumothorax, bronchial obstruction, diaphragmatic paresis, and vocal cord paralysis. ${ }^{37}$ Moreover, in a subset of patients, lung compliance worsens following ligation and may require increased ventilator support. ${ }^{41,42}$ Postcardiac ligation syndrome complicates $28-45 \%$ of all ductus arteriosus ligations and is characterized by symptoms including systemic hypotension with deficits in oxygenation or ventilation within $6-24 \mathrm{~h}$ following the procedure. ${ }^{43-45}$ In a case-control analysis comparing premature infants receiving conventional mechanical ventilation and $\mathrm{HFV}$, Hsu et $\mathrm{al}^{46}$ reported that rescue HFV was independently predictive of improvement in respiratory status at $7 \mathrm{~d}$ (odds ratio 5.03, 95\% CI 1.14-22.2), whereas infants in the conventional mechanical ventilation group required escalations in mean airway pressure and $\mathrm{F}_{\mathrm{IO}_{2}}$ during the first 2-3 $\mathrm{d}$ following ligation. In line with our findings, it is plausible that early rescue HFV may be most beneficial for infants with worse lung disease and patent ductus arteriosus by maintaining stable gas exchange perioperatively and thereby preventing further respiratory deterioration.

It is important to note the limitations of the current study. This study was retrospective and therefore reliant on the accuracy of the medical records. This design introduces the potential for selection bias and is uncontrolled. We attempted to limit selection bias with inclusion and exclusion criteria. Further, we utilized logistic regression analysis to control and adjust for covariates. The sample size

$(n=53)$ is somewhat small; however, HFJV represents a niche area of research, and most modern studies are only able to practically enroll a limited number of subjects. ${ }^{36,47,48}$ All subjects were outborn, which has been associated with poorer survival and a higher rate of morbidities including necrotizing enterocolitis, retinopathy of prematurity, and severe intraventricular hemorrhage. ${ }^{49}$ As such, our findings may be more applicable to large referral centers with a heterogeneous case mix. Our results are reflective of institutional practice and guidelines that suggest HFJV is a viable strategy in patients with persistent respiratory failure refractory to conventional mechanical ventilation. However, we cannot determine with absolute certainty that subjects improved as a direct result of HFJV because we did not have a control group of subjects who continued to receive conventional mechanical ventilation, nor did we compare rescue HFJV with HFOV. The multivariate risk score needs to be validated in other cohorts to assess performance. The accuracy of OSI can be affected by the relationship between $\mathrm{S}_{\mathrm{pO}_{2}}$ and $\mathrm{P}_{\mathrm{a}}$ on the oxygen-disassociation curve, signal quality from the pulse oximeter, the presence of fetal hemoglobin, transfusion, and temperature. Long-term follow-up was limited due to the nature of the study, and a significant proportion of subjects were transferred back to the referring hospital prior to 36 weeks postmenstrual age. Therefore, we provided descriptive statistics for respiratory outcomes and were not able to assess long-term pulmonary, neurologic, or developmental outcomes. It is also desirable to perform stratified analyses based on the degree of prematurity of the subjects as well as weight. 


\section{Mortality Risk Factors in Preterm InFAnts Treated with HFJV}

We were unable to provide these analyses due to the limited sample size. Future investigations, with a larger sample and a higher number of deaths, are needed to address this issue.

HFV has been used extensively in addition to other conventional modes of neonatal ventilation. Future research is needed to delineate the optimal mode and parameters associated with rescue HFV in a context specific to the underlying physiology and disease state. In the absence of prospective randomized controlled trials to evaluate differences between HFV modalities, retrospective and prospective cohort studies are required. These studies can be hypothesis-generating insofar as early identification of infants who may benefit most from HFV and to identify criteria associated with morbidity and mortality. Indeed, further studies are required to compare ventilation strategies and respiratory outcomes for premature infants with patent ductus arteriosus.

\section{Conclusions}

We observed that an OSI $>5.5$ at $4 \mathrm{~h}$ following transition to HFJV, closed ductus arteriosus, and female sex were independent predictors of mortality. These attributes were included in a multivariate risk score that demonstrated excellent predictive ability for mortality in our study population. The proposed risk model may facilitate early identification of infants who may benefit most from HFJV and those at high-risk for mortality. OSI is a useful noninvasive metric for guiding interventions, evaluating treatment response, and determining risk stratification in premature infants.

\section{REFERENCES}

1. Stoll BJ, Hansen NI, Bell EF, Walsh MC, Carlo WA, Shankaran S, et al. Trends in care practices, morbidity, and mortality of extremely preterm neonates, 1993-2012. JAMA 2015;314(10):1039-1051.

2. Tracy MK, Berkelhamer SK. Bronchopulmonary dysplasia and pulmonary outcomes of prematurity. Pediatr Ann 2019;48(4):e148-e153.

3. Committee on Fetus and Newborn; American Academy of Pediatrics. Respiratory support in preterm infants at birth. Pediatrics 2014;133 (1):171-174

4. Jensen EA. Prevention of bronchopulmonary dysplasia: a summary of evidence-based strategies. Neoreviews 2019;20(4):e189-e201.

5. Dargaville PA, Gerber A, Johansson S, De Paoli AG, Kamlin CO, Orsini F, Davis PG, for the Australian and New Zealand Neonatal Network. Incidence and outcome of CPAP failure in preterm infants. Pediatrics 2016;138(1):e20153985.

6. Moya FR, Mazela J, Shore PM, Simonson SG, Segal R, Simmons PD, et al. Prospective observational study of early respiratory management in preterm neonates less than 35 weeks of gestation. BMC Pediatr 2019;19(1): 147

7. Chawla S, Natarajan G, Shankaran S, Carper B, Brion LP, Keszler M, et al. Markers of successful extubation in extremely preterm infants, and morbidity after failed extubation. J Pediatr 2017;189:113-119. e112.
8. Rojas-Reyes MX, Orrego-Rojas PA. Rescue high-frequency jet ventilation vs conventional ventilation for severe pulmonary dysfunction in preterm infants. Cochrane Database Syst Rev 2015;10:CD000437.

9. Cools F, Offringa M, Askie LM. Elective high frequency oscillatory ventilation vs conventional ventilation for acute pulmonary dysfunction in preterm infants. Cochrane Database Syst Rev 2015;3: CD000104.

10. Patel RM, Kandefer S, Walsh MC, Bell EF, Carlo WA, Laptook AR, et al. Causes and timing of death in extremely premature infants from 2000 through 2011. N Engl J Med 2015;372(4):331-340.

11. Glass HC, Costarino AT, Stayer SA, Brett CM, Cladis F, Davis PJ. Outcomes for extremely premature infants. Anesth Analg 2015;120 (6): 1337-1351.

12. Wheeler CR, Smallwood CD, O'Donnell I, Gagner D, Sola-Visner MC. Assessing initial response to high-frequency jet ventilation in premature infants with hypercapnic respiratory failure. Respir Care 2017;62(7):867-872.

13. Ehrenkranz RA, Walsh MC, Vohr BR, Jobe AH, Wright LL, Fanaroff AA. Validation of the National Institutes of Health consensus definition of bronchopulmonary dysplasia. Pediatrics 2005;116(6):13531360.

14. Jobe AH, Bancalari E. Bronchopulmonary dysplasia. Am J Respir Crit Care Med 2001;163(7):1723-1729.

15. Manley BJ, Doyle LW, Owen LS, Davis PG. Extubating extremely preterm infants: predictors of success and outcomes following failure. J Pediatr 2016;173:45-49.

16. Ethawi YH, Abou Mehrem A, Minski J, Ruth CA, Davis PG. High frequency jet ventilation vs high frequency oscillatory ventilation for pulmonary dysfunction in preterm infants. Cochrane Database Syst Rev 2016;5:CD010548.

17. Stoll BJ, Hansen NI, Bell EF, Shankaran S, Laptook AR, Walsh MC, et al. Neonatal outcomes of extremely preterm infants from the NICHD Neonatal Research Network. Pediatrics 2010;126(3):443-456.

18. Townsel CD, Emmer SF, Campbell WA, Hussain N. Gender differences in respiratory morbidity and mortality of preterm neonates. Front Pediatr 2017;5:6.

19. Erdeve O, Okulu E, Tunc G, Celik Y, Kayacan U, Cetinkaya M, et al. An observational, prospective, multicenter study on rescue high-frequency oscillatory ventilation in neonates failing with conventional ventilation. PloS One 2019;14(6): e0217768.

20. Willson DF, Thomas NJ, Markovitz BP, Bauman LA, DiCarlo JV, Pon S, et al. Effect of exogenous surfactant (calfactant) in pediatric acute lung injury: a randomized controlled trial. JAMA 2005;293 (4):470-476.

21. Stewart DL, Dela Cruz TV, Duncan SD, Cook LN. Response to high frequency jet ventilation may predict the need for extracorporeal membrane oxygenation. Eur Respir J 1996;9(6):1257-1260.

22. Golombek SG, Young JN. Efficacy of inhaled nitric oxide for hypoxic respiratory failure in term and late preterm infants by baseline severity of illness: a pooled analysis of three clinical trials. Clin Ther 2010;32 (5):939-948

23. Shahid S, Dutta S, Symington A, Shivananda S, McMaster University NICU. Standardizing umbilical catheter usage in preterm infants. Pediatrics 2014;133(6):e1742-1752.

24. de Brito CS, de Brito DV, Abdallah VO, Gontijo Filho PP. Occurrence of bloodstream infection with different types of central vascular catheter in critically neonates. J Infect 2010;60(2):128-132.

25. Deindl P, Waldhor T, Unterasinger L, Berger A, Keck M. Arterial catheterisation in neonates can result in severe ischaemic complications but does not impair long-term extremity function. Acta Paediatr 2018;107(2):240-248.

26. Rawat M, Chandrasekharan PK, Williams A, Gugino S, Koenigsknecht C, Swartz D, et al. Oxygen saturation index and severity of hypoxic respiratory failure. Neonatology 2015;107(3):161-166. 


\section{Mortality Risk Factors in Preterm InFAnTS TREATED with HFJV}

27. Doreswamy SM, Chakkarapani AA, Murthy P. Oxygen saturation index, a noninvasive tool for monitoring hypoxemic respiratory failure in newborns. Indian Pediatr 2016;53(5):432-433.

28. Khemani RG, Thomas NJ, Venkatachalam V, Scimeme JP, Berutti T, Schneider JB, et al. Comparison of $\mathrm{SpO} 2$ to $\mathrm{PaO} 2$ based markers of lung disease severity for children with acute lung injury. Crit Care Med 2012;40(4):1309-1316.

29. Muniraman HK, Song AY, Ramanathan R, Fletcher KL, Kibe R, Ding $\mathrm{L}$, et al. Evaluation of oxygen saturation index compared with oxygenation index in neonates with hypoxemic respiratory failure. JAMA Netw Open 2019;2(3):e191179.

30. Khalesi N, Choobdar FA, Khorasani M, Sarvi F, Haghighi Aski B, Khodadost M. Accuracy of oxygen saturation index in determining the severity of respiratory failure among preterm infants with respiratory distress syndrome. J Matern Fetal Neonatal Med 2019:1-6.

31. Mirza H, Garcia J, McKinley G, Hubbard L, Sensing W, Schneider J, et al. Duration of significant patent ductus arteriosus and bronchopulmonary dysplasia in extremely preterm infants. J Perinatol 2019;39 (12): 1648-1655.

32. Giesinger RE, Bischoff AR, McNamara PJ. Anticipatory perioperative management for patent ductus arteriosus surgery: understanding postligation cardiac syndrome. Congenit Heart Dis 2019;14(2):311-316.

33. de Waal K, Evans N, van der Lee J, van Kaam A. Effect of lung recruitment on pulmonary, systemic, and ductal blood flow in preterm infants. J Pediatr 2009;154(5):651-655.

34. de Waal KA, Evans N, Osborn DA, Kluckow M. Cardiorespiratory effects of changes in end expiratory pressure in ventilated newborns. Arch Dis Child Fetal Neonatal Ed 2007;92(6):F444-F448.

35. Fajardo MF, Claure N, Swaminathan S, Sattar S, Vasquez A, D’Ugard $\mathrm{C}$, et al. Effect of positive end-expiratory pressure on ductal shunting and systemic blood flow in preterm infants with patent ductus arteriosus. Neonatology 2014;105(1):9-13.

36. Noonan M, Turek JW, Dagle JM, McElroy SJ. Intraoperative high-frequency jet ventilation is equivalent to conventional ventilation during patent ductus arteriosus ligation. World J Pediatr Congenit Heart Surg 2017;8(5):570-574.

37. Vali $\mathrm{P}$, Lakshminrusimha $\mathrm{S}$, Pelech $\mathrm{A}$, Underwood M, Ing F. Patent ductus arteriosus in preterm infants: is early transcatheter closure a paradigm shift? J Perinatol 2019;39(11):1449-1461.
38. Naulty CM, Horn S, Conry J, Avery GB. Improved lung compliance after ligation of patent ductus arteriosus in hyaline membrane disease. J Pediatr 1978;93(4):682-684.

39. Gerhardt T, Bancalari E. Lung compliance in newborns with patent ductus arteriosus before and after surgical ligation. Biol Neonate 1980;38(1-2):96-105.

40. Lehenbauer DG, Fraser CD 3rd, Crawford TC, Hibino N, Aucott S, Grimm JC, et al. Surgical closure of patent ductus arteriosus in premature neonates weighing less than 1,000 grams: contemporary outcomes. World J Pediatr Congenit Heart Surg 2018;9(4):419-423.

41. Szymankiewicz M, Hodgman JE, Siassi B, Gadzinowski J. Mechanics of breathing after surgical ligation of patent ductus arteriosus in newborns with respiratory distress syndrome. Biology of the Neonate 2004;85(1):32-36.

42. Heuchan AM, Hunter L, Young D. Outcomes following the surgical ligation of the patent ductus arteriosus in premature infants in Scotland. Arch Dis Child Fetal Neonatal Ed 2012;97(1):F39-F44.

43. Ulrich TJB, Hansen TP, Reid KJ, Bingler MA, Olsen SL. Post-ligation cardiac syndrome is associated with increased morbidity in preterm infants. J Perinatol 2018;38(5):537-542.

44. Harting MT, Blakely ML, Cox CS Jr, Lantin-Hermoso R, Andrassy RJ, Lally KP. Acute hemodynamic decompensation following patent ductus arteriosus ligation in premature infants. J Invest Surg 2008;21 (3):133-138.

45. Clyman RI, Wickremasinghe A, Merritt TA, Solomon T, McNamara $\mathrm{P}$, Jain A, et al. Hypotension following patent ductus arteriosus ligation: the role of adrenal hormones. J Pediatr 2014;164(6):1449-1455.

46. Hsu KH, Wong P, Ram Kumar S, Evans J, Noori S. Predictors of respiratory improvement 1 week after ligation of patent ductus arteriosus in preterm infants. J Pediatr 2019;205:49-54.

47. Attar MA, Dechert RE, Donn SM. Rescue high frequency ventilation for congenital diaphragmatic hernia. J Neonatal Perinatal Med 2019;12(2):173-178.

48. Anvekar AP, Shah PS, Nathan EA, Doherty DA, Patole SK, Simmer $\mathrm{KN}$. High frequency jet ventilation in preterm infants: experience from Western Australia. J Matern Fetal Neonatal Med 2019;32 (17):2824-2829.

49. Fang JL, Mara KC, Weaver AL, Clark RH, Carey WA. Outcomes of outborn extremely preterm neonates admitted to a NICU with respiratory distress. Arch Dis Child Fetal Neonatal Ed 2020;105(1):33-40.

This article is approved for Continuing Respiratory Care Education credit. For information and to obtain your CRCE

(free to AARC members) visit

www.rcjournal.com

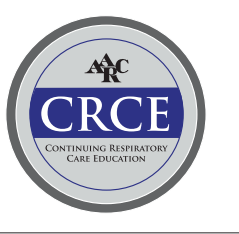

